\title{
Effect of the temperature of sodium hypochlorite on the cyclic fatigue resistance of ProTaper Gold rotary files
}

\author{
Seyed Amir Mousavi ${ }^{1, A}$, Niloofar Norouzi ${ }^{1, B, D}$, Bahareh Memarzadeh ${ }^{1, C}$, Seyed Rohollah Havaei ${ }^{1, E}$, Hazhir Yousefshahi ${ }^{2, C, E}$ \\ ${ }^{1}$ Dental Research Center, Department of Endodontics, School of Dentistry, Isfahan University of Medical Sciences, Iran \\ ${ }^{2}$ Department of Endodontics, School of Dentistry, Islamic Azad University of Medical Sciences, Tehran, Iran \\ A - research concept and design; $\mathrm{B}$ - collection and/or assembly of data; $\mathrm{C}$ - data analysis and interpretation; \\ $D$ - writing the article; $E$ - critical revision of the article; $F$ - final approval of the article
}

Address for correspondence

Niloofar Norouzi

E-mail:niloofar.norouzi95@gmail.com

Funding sources

None declared

Conflict of interest

None declared

Received on December 29, 2019

Reviewed on February 25, 2020

Accepted on August 10, 2020

Published online on December 31, 2021

Cite as

Mousavi SA, Norouzi N, Memarzadeh B, Havaei SR, Yousefshahi H.

Effect of the temperature of sodium hypochlorite on the cyclic fatigue resistance of ProTaper Gold rotary files. Dent Med Probl. 2021;58(4):533-537. doi:10.17219/dmp/126260

DOI

$10.17219 / \mathrm{dmp} / 126260$

Copyright

○) 2021 by Wroclaw Medical University

This is an article distributed under the terms of the

Creative Commons Attribution 3.0 Unported License (CC BY 3.0)

(https://creativecommons.org/licenses/by/3.0/).

\begin{abstract}
Background. Instrument fracture is one of major challenges during root canal treatment. In order to reduce such errors, it seems necessary to investigate the effects of potentially impactful factors. One of such factors could be the temperature of an agitator.

Objectives. This study examined the effects of different temperature of the sodium hypochlorite solution on the cyclic fatigue resistance of ProTaper Gold (PTG) rotary files.

Material and methods. Forty-five PTG S1 rotary files were tested in a metal block that simulated a canal curvature angle of $60^{\circ}$ and a curvature radius of $5 \mathrm{~mm}$. They were randomly divided into 3 groups of 15 according to sodium hypochlorite temperatures of $22^{\circ} \mathrm{C}$ (group 1), $4^{\circ} \mathrm{C}$ (group 2) and $37^{\circ} \mathrm{C}$ (group 3). Files from each group were rotated at $300 \mathrm{rpm}$ in the block at each temperature. The number of cycles to fracture was calculated and the fragment length was measured. The fractured surfaces were examined by means of scanning electron microscopy (SEM). The statistical analysis was completed using the Kolmogorov-Smirnov and Kruskal-Wallis tests, and the IBM SPSS Statistics for Windows software, v. 22.0, at a significance level of $5 \%$.

Results. The cyclic fatigue resistance of the PTG rotary files was not significantly affected by the temperature of sodium hypochlorite $(p>0.05)$.

Conclusions. Increasing the temperature of sodium hypochlorite to $37^{\circ} \mathrm{C}$ or decreasing it to $4^{\circ} \mathrm{C}$ did not significantly affect the cyclic fatigue resistance of PTG rotary files.
\end{abstract}

Keywords: temperature, sodium hypochlorite, rotary instruments, cyclic fatigue, nickel-titanium 


\section{Introduction}

One of the most important goals in root canal therapy is to reduce the microbial load in the root canal system to an acceptable level. One important step in achieving this goal is the cleaning and shaping of the root canal. ${ }^{1}$ Currently, rotary files are widely used for shaping root canals. ${ }^{1,2}$ Research has shown that nickel-titanium (NiTi) rotary files result in fewer procedural errors during the preparation and shaping of root canals, and more favorable outcomes as compared to stainless-steel files. ${ }^{1-3}$ However, the use of rotary files may be associated with problems, such as file fracture within the root canal. ${ }^{4}$

The fracture of rotary files within the root canal can have 2 forms - torsional fracture and cyclic fatigue fracture. Torsional fracture occurs when the file tip is engaged in the root canal and the file shank is in rotation, leading to the fracture of the file tip. Cyclic fatigue fracture occurs when the file undergoes repeated stress and tension, and fractures within the root canal. Cyclic fatigue is responsible for the majority of fractures. Many studies have been undertaken in an attempt to reduce the risk of this type of fracture. ${ }^{4-7}$

Root canal therapy is most commonly performed using irrigation solutions, with sodium hypochlorite being the most freqeuntly used. ${ }^{1}$ This irrigation solution exhibits high antibacterial activity and strong tissue solubility. Furthermore, according to some studies, its antibacterial activity and tissue solubility increase with an increase in temperature. ${ }^{5,8}$ Some studies have reported that the sodium hypochlorite solution can cause the corrosion of $\mathrm{Ni}$ - $\mathrm{Ti}$ files due to its hypochlorite ion content. This would affect its mechanical properties and increase the odds of a sudden fracture. ${ }^{9}$ Other studies, however, have reported that the sodium hypochlorite solution does not have any effect on the structure of heat-treated files. ${ }^{10}$

ProTaper Gold (PTG; Dentsply Tulsa Dental Specialties, Tulsa, USA) is a new generation of ProTaper rotary files. According to the manufacturer, PTG files have been designed based on advanced metallurgy and exclusive tapering, with high efficacy and a safe tip. Due to the heattreatment process, the shape memory and higher plasticity associated with these files reduce the number of the preparation errors in curved canals. In addition, this generation of files is more flexible than the ProTaper Universal file type. ${ }^{11,12}$

Continuous advances in rotary file systems and their ever-increasing use have made it possible to decrease the number of procedural errors. Also, according to previous studies, an increase in the temperature of the sodium hypochlorite solution reduces the microbial load. On the other hand, a decrease in the file temperature reduces friction and failure during root canal treatment steps. ${ }^{13,14}$ A limited number of studies have investigated the effect of temperature variations on the fracture resistance of these files. Therefore, the aim of this study was to investigate the effect of the temperature of the sodium hypochlorite solution on the fracture resistance of PTG rotary files.

\section{Material and methods}

Forty-five PTG S1 rotary files were tested in this study. The samples were examined using a scanning electron microscope (SEM) (Leica M205 C; Leica Microsystems, Wetzlar, Germany) for structural defects or deformities. Defective files were replaced by new ones with no structural defects.

The specimens were randomly divided into 3 groups $(n=15)$. A sodium hypochlorite (Wizard ${ }^{\mathrm{TM}}$; Rehber Kimya, Istanbul, Turkey) solution was used at $22^{\circ} \mathrm{C}$ (room temperature) in group 1 , at $4^{\circ} \mathrm{C}$ in group 2 , and at $37^{\circ} \mathrm{C}$ (body temperature within the root canal) in group 3 . The concentration of the sodium hypochlorite solution was $5.25 \%$ for all groups.

For the cyclic fatigue test, a stainless-steel metal block with a simulated canal with a curvature angle of $60^{\circ}$, a curvature radius of $5 \mathrm{~mm}$ and a length of $25 \mathrm{~mm}$ was used (Fig. 1). It was designed in such a way so that the file could move freely within the canal. The file was inserted into a handpiece connected to an endodontic motor (Silver; VDW, Munich, Germany). The block and handpiece were fixed in place with a clamp. The engine speed was set at $300 \mathrm{rpm}$ and a torque of $5.1 \mathrm{~N} \cdot \mathrm{cm}$, based on the manufacturer's recommendations. Before starting the procedure, oil was poured into the canal to reduce friction. The file was inserted into the canal up to a length of $25 \mathrm{~mm}$. The block was fixed inside a recipient that was filled with $5.25 \%$ sodium hypochlorite. The temperature was preset at $22^{\circ} \mathrm{C}, 4^{\circ} \mathrm{C}$ and $37^{\circ} \mathrm{C}$ with a tolerance limit of $1^{\circ} \mathrm{C}$. Time was measured with a timer, starting from the moment when the file began to rotate. The timer was stopped a fracture was observed or after hearing a fracture sound, and the time was recorded. The time in minutes was multiplied by $300 \mathrm{rpm}$ to calculate the number of cycles to fracture (NCF). The fragment length was measured under an SEM (Leica M205 C) at $\times 10$ magnification. The 3 fractured instruments were cleaned with absolute alcohol in an ultrasonic bath. The fractured surface was examined using an SEM (Leica M205 C), as demonstrated in Fig. 2-7.

\section{Statistical analysis}

The mean $(M)$ and standard deviation $(S D)$ values were calculated in terms of NCF. The distribution of data was abnormal, as confirmed by the Kolmogorov-Smirnov test. The data was analyzed with the Kruskal-Wallis test. A confidence level of $95 \%$ was established. The IBM SPSS Statistics for Windows software, v. 22.0 (IBM Corp., Armonk, USA), was used for data analysis. 


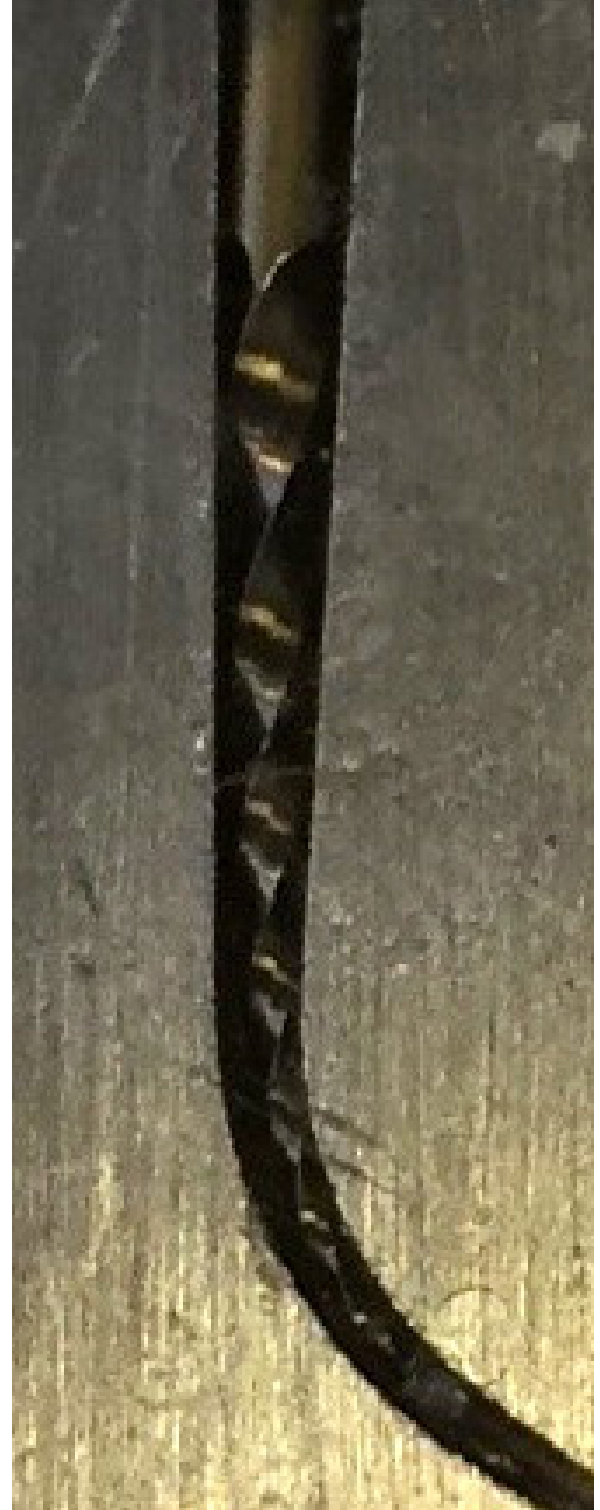

Fig. 1. Artificial stainless-steel canal

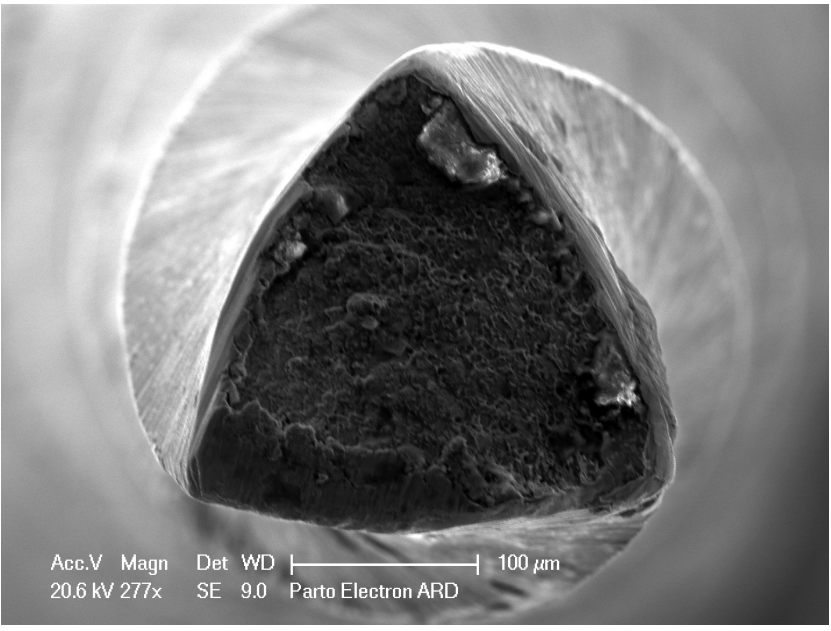

Fig. 2. Scanning electron microscopy (SEM) image of the ProTaper Gold (PTG) S1 instrument after cyclic fatigue testing using $\mathrm{NaOCl}$ at $4^{\circ} \mathrm{C}$ $\times 277$ magnification.

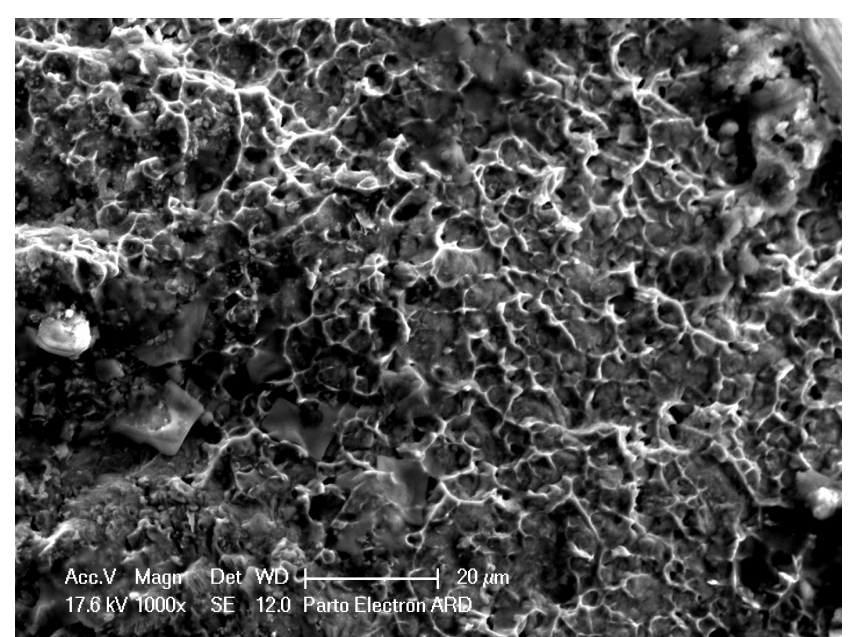

Fig. 3. Scanning electron microscopy (SEM) image of the ProTaper Gold (PTG) $\mathrm{S} 1$ instrument after cyclic fatigue testing using $\mathrm{NaOCl}$ at $4^{\circ} \mathrm{C}$ $\times 1,000$ magnification.

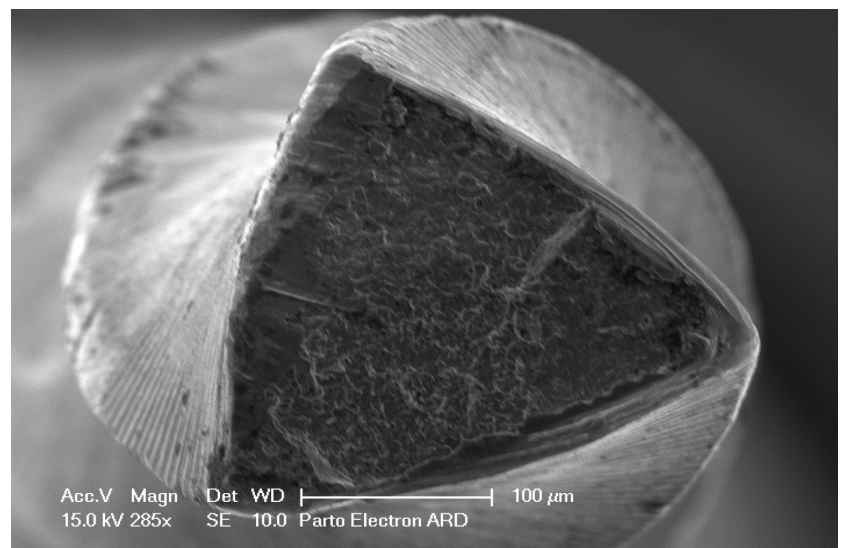

Fig. 4. Scanning electron microscopy (SEM) image of the ProTaper Gold (PTG) S1 instrument after cyclic fatigue testing using $\mathrm{NaOCl}$ at $22^{\circ} \mathrm{C}$ $\times 285$ magnification.

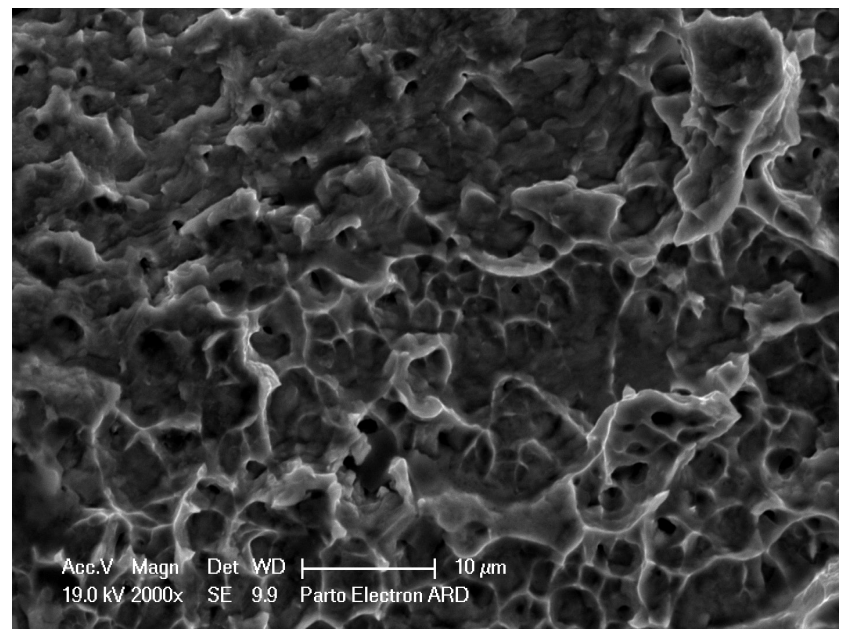

Fig. 5. Scanning electron microscopy (SEM) image of the ProTaper Gold (PTG) S1 instrument after cyclic fatigue testing using $\mathrm{NaOCl}$ at $22^{\circ} \mathrm{C}$ $\times 2,000$ magnification. 


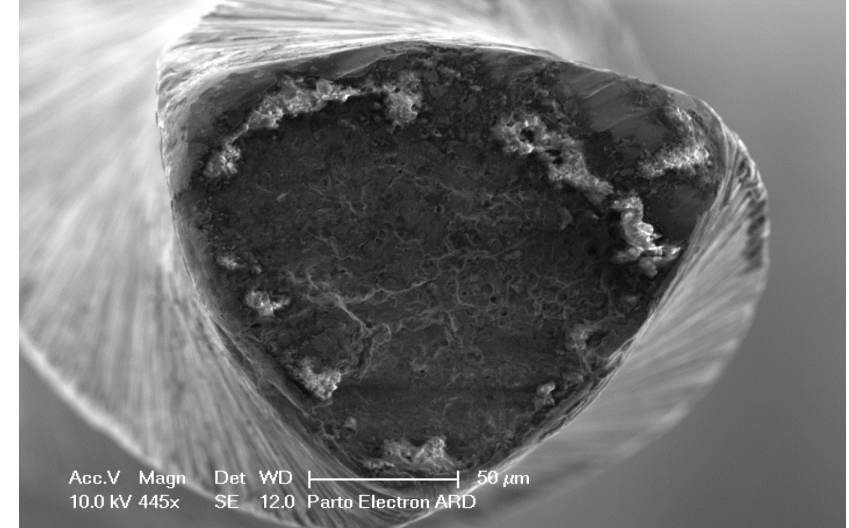

Fig. 6. Scanning electron microscopy (SEM) image of the ProTaper Gold (PTG) $\mathrm{S} 1$ instrument after cyclic fatigue testing using $\mathrm{NaOCl}$ at $37^{\circ} \mathrm{C}$ $\times 445$ magnification.

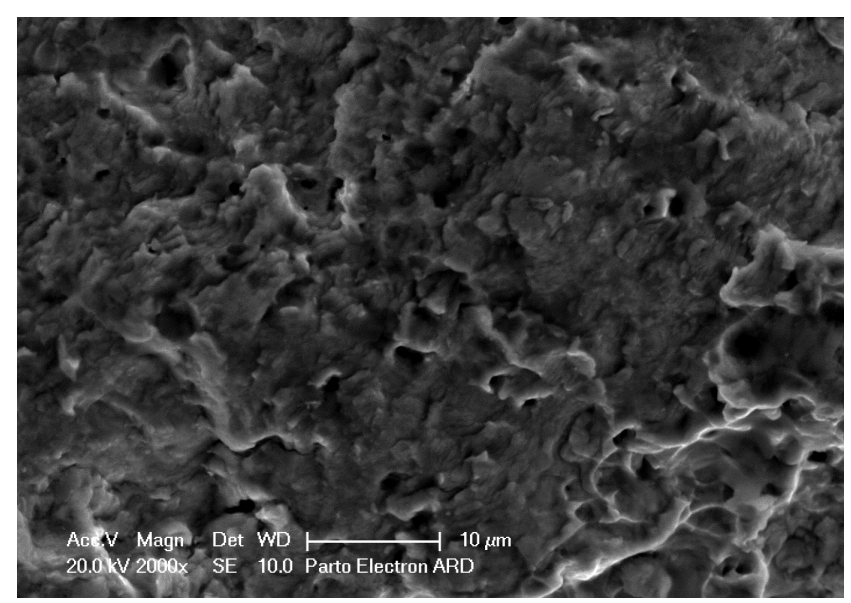

Fig. 7. Scanning electron microscopy (SEM) image of the ProTaper Gold (PTG) $\mathrm{S} 1$ instrument after cyclic fatigue testing using $\mathrm{NaOCl}$ at $37^{\circ} \mathrm{C}$ $\times 2,000$ magnification

\section{Results}

The $M$ and $S D$ values for NFC are presented in Table 1. The mean fracture resistance in group 1 was slightly higher than that in the other groups. The mean fracture resistance in group 2 was slightly lower than that in the other 2 groups; however, there were no significant differences in the mean NCF values between the 3 groups $(p>0.05)$. Table 1 presents the mean length of the broken pieces at $22^{\circ} \mathrm{C}, 4^{\circ} \mathrm{C}$ and $37^{\circ} \mathrm{C}$; there was no statistically significant difference between the 3 groups in this respect $(p>0.05)$.

Table 1. Number of cycles to fracture (NCF) and length of the broken pieces in all study groups

\begin{tabular}{|c|c|c|}
\hline Group & NCF & $\begin{array}{c}\text { Length of the fractured piece } \\
{[\mathrm{mm}]}\end{array}$ \\
\hline Group 1 & $1248.50000 \pm 299.17526$ & $4.42 \pm 0.45$ \\
Group 2 & $1076.50000 \pm 190.93411$ & $4.98 \pm 0.56$ \\
Group 3 & $1119.50000 \pm 117.81174$ & $4.48 \pm 0.71$ \\
\hline
\end{tabular}

Data presented as mean \pm standard deviation $(M \pm S D)$.

Group $1-\mathrm{NaOCl}$ at $22^{\circ} \mathrm{C}$; group $2-\mathrm{NaOCl}$ at $4^{\circ} \mathrm{C}$; group $3-\mathrm{NaOCl}$ at $37^{\circ} \mathrm{C}$.

\section{Discussion}

The introduction of rotary files has resulted in faster root canal therapy and fewer procedural errors during root canal preparation. One of the most common errors during root canal therapy is file fracture within the root canal. The highest probability of fracture is related to fatigue. Factors that affect fatigue resistance include the canal curvature, the length and anatomy of the root canal, the frequency of file use, the design of the file, the metal alloys used in the file, the sterilization process, the rotary machine factors, and the operator's experience. ${ }^{15-18}$

Recently, the effect of environmental temperature has been investigated as a factor affecting fracture resistance. ${ }^{10,19}$ The majority of these studies have investigated the effect of temperatures higher than the temperature within the root canal. A temperature of $4^{\circ} \mathrm{C}$ is considered a low temperature of the sodium hypochlorite solution; also, the sodium hypochlorite solution is stable at this temperature..$^{20}$ Temperatures of $37^{\circ} \mathrm{C}$ and $22^{\circ} \mathrm{C}$ are considered root canal and environmental temperatures, respectively. A concentration of $5.25 \%$ was selected for the sodium hypochlorite solution in this study, since it is commonly used in root canal therapy. ${ }^{21}$

In this study, fatigue resistance was determined with a device that was similar to that used in previous studies. $^{1,8,22}$ The length of the broken pieces was not significantly different between the groups, which indicates the presence of a similar location of stress in the root canal, i.e., the middle of the curvature in the root canal, which is consistent with previous studies. ${ }^{10,22}$

Previous clinical studies have shown that when the irrigation solution is delivered into the root canal at different temperatures, the body tends to balance its temperature with the temperature within the canal, which is around $35^{\circ} \mathrm{C}$. ${ }^{21}$ One of the factors that can influence fracture resistance is the temperature at conversion from the austenitic phase to the martensitic phase during the fabrication of the file alloy. If this temperature is between room temperature and the temperature within the root canal, the file temperature reaches the phase transition temperature when the file is inserted into the canal, resulting in a decrease in fatigue resistance and an increase in the odds of fracture. ${ }^{23}$

One of the advantages of PTG Gold files over previous generations is that its phase transition temperature is higher than the temperature within the root canal. ${ }^{23}$ In this study, unlike in previous studies, the temperature of the solution did not affect the fracture resistance of the files, which might be attributed to the phase transition temperature; therefore, in heat-treated files, temperature has a lesser effect on the fracture resistance of the files. ${ }^{24}$

In another study, the effect of 3 temperatures of the sodium hypochlorite solution $\left(22^{\circ} \mathrm{C}, 37^{\circ} \mathrm{C}\right.$ and $\left.50^{\circ} \mathrm{C}\right)$ on the fracture resistance of files was investigated. ${ }^{14}$ It was reported that a temperature of $37^{\circ} \mathrm{C}$ had no effect on fracture resistance, which is consistent with the results of the present study, while a temperature of $50^{\circ} \mathrm{C}$ increased the fracture 
resistance of the rotary files. ${ }^{14}$ Another study determined that a decrease in environmental temperature to $0^{\circ} \mathrm{C}$ increased the fracture resistance of the tested files. ${ }^{19}$

Previous studies have shown that contact between the sodium hypochlorite solution and $\mathrm{Ni}$ - $\mathrm{Ti}$ files might result in the corrosion of the files. If this corrosion does not occur in the area of file which is affected by high stress, it cannot affect the fracture resistance of the file. ${ }^{9}$ According to the manufacturer's claims, in newer generations, files do not undergo corrosion due to more advanced metallurgy. For example, a study on the effect of high concentrations of the sodium hypochlorite solution at $22^{\circ} \mathrm{C}, 37^{\circ} \mathrm{C}$ and $50^{\circ} \mathrm{C}$ determined that the concentration of the sodium hypochlorite solution did not affect the fracture resistance of rotary files, which is consistent with the results of the present study. ${ }^{4}$

A similar study compared the effects of environmental temperature and the temperature within the root canal on the fracture resistance of ProTaper Universal and PTG files. ${ }^{23}$ It concluded that temperature did not affect the fracture resistance of PTG files, while increasing the temperature decreased the fracture resistance of ProTaper Universal files, which is consistent with the results of the present study. ${ }^{23}$

Since the fracture resistance of files depends on different factors, including the type of file and the method applied in the study, it is suggested that other files and temperatures should also be evaluated. In addition, since this study was carried out in vitro, it is suggested that, if possible, clinical studies should be carried out on vital teeth.

\section{Conclusions}

Increasing the temperature of the sodium hypochlorite solution to $37^{\circ} \mathrm{C}$ or decreasing it to $4^{\circ} \mathrm{C}$ did not significantly affect the fracture resistance of PTG rotary files. In addition, the length of the broken pieces was not significantly different between the 3 groups. Since this study was carried out in vitro, it is suggested that further clinical studies be undertaken on vital teeth.

\section{ORCID iDs}

Seyed Amir Mousavi (1) https://orcid.org/0000-0003-4456-9648 Niloofar Norouzi (1) https://orcid.org/0000-0002-2781-6830 Bahareh Memarzadeh (1) https://orcid.org/0000-0003-2774-0255 Seyed Rohollah Havaei (i) https://orcid.org/0000-0003-3662-8185 Hazhir Yousefshahi (1) https://orcid.org/0000-0002-7367-5768

\section{References}

1. Pedullà E, Grande NM, Plotino G, Pappalardo A, Rapisarda E. Cyclic fatigue resistance of three different nickel-titanium instruments after immersion in sodium hypochlorite. J Endod. 2011;37(8):1139-1142. doi:10.1016/j.joen.2011.04.008

2. Peters OA. Current challenges and concepts in the preparation of root canal systems: A review. J Endod. 2004;30(8):559-567. doi:10.1097/01.don.0000129039.59003.9d

3. Pettiette MT, Metzger Z, Phillips C, Trope M. Endodontic complications of root canal therapy performed by dental students with stainless-steel K-files and nickel-titanium hand files. J Endod. 1999;25(4):230-234. doi:10.1016/S0099-2399(99)80148-4
4. Huang X, Shen Y, Wei X, Haapasalo M. Fatigue resistance of nickeltitanium instruments exposed to high-concentration hypochlorite. J Endod. 2017;43(11):1847-1851. doi:10.1016/j.joen.2017.06.033

5. Galvão Barbosa FO, da Cunha Ponciao Gomes JA, Pimenta de Araújo MC. Influence of sodium hypochlorite on mechanical properties of K3 nickel-titanium rotary instruments. J Endod. 2007;33(8):982-985. doi:10.1016/j.joen.2007.05.008

6. Cheung GSP, Darvell BW. Fatigue testing of a NiTi rotary instrument. Part 1: Strain-life relationship. Int Endod J. 2007;40(8):612-618. doi:10.1111/j.1365-2591.2007.01262.x

7. Cheung GSP, Peng B, Bian Z, Shen Y, Darvell BW. Defects in ProTaper S1 instruments after clinical use: Fractographic examination. Int Endod J. 2005;38(11):802-809. doi:10.1111/j.1365-2591.2005.01020.x

8. Giardino L, Mohammadi Z, Beltrami R, Poggio C, Estrela C, Generali L. Influence of temperature on the antibacterial activity of sodium hypochlorite. Braz Dent J. 2016;27(1):32-36. doi:10.1590/0103-6440201600627

9. Bulem UK, Kececi AD, Guldas HE. Experimental evaluation of cyclic fatigue resistance of four different nickel-titanium instruments after immersion in sodium hypochlorite and/or sterilization. $J$ Appl Oral Sci. 2013;21(6):505-510. doi:10.1590/1679-775720130083

10. Grande NM, Plotino G, Silla E, et al. Environmental temperature drastically affects flexural fatigue resistance of nickel-titanium rotary files. J Endod. 2017;43(7):1157-1160. doi:10.1016/j.joen.2017.01.040

11. Elnaghy AM, Elsaka SE. Mechanical properties of ProTaper Gold nickel-titanium rotary instruments. Int Endod J. 2016;49(11):1073-1078. doi:10.1111/iej.12557

12. Hieawy A, Haapasalo M, Zhou H, Wang ZJ, Shen Y. Phase transformation behavior and resistance to bending and cyclic fatigue of ProTaper Gold and ProTaper Universal instruments. J Endod. 2015;41(7):1134-1138. doi:10.1016/j.joen.2015.02.030

13. Amini K, Fathi MH, Zare JM, Mousavi A, Kamali A. Evaluation of the effect of cryogenic treatment on cutting efficacy of Ni-Ti rotary files. J Isfahan Dent Sch. 2013;9(1):1-10.

14. Mousavi SA, Kargar-Dehnavi V, Mousavi SA. A novel approach to determine the effect of irrigation on temperature and failure of Ni-Ti endodontic rotary files. Dent Res J (Isfahan). 2012;9(3):281-287. PMID:23087732. PMCID:PMC3469893.

15. Demiral M, Keskin C, Inan U. Effect of sodium hydrochlorite activated by heating on the cyclic fatigue resistance of OneShape rotary instrument. J Dent App. 2017;4(1):372-375. https://www.austinpublishinggroup.com/dental-applications/fulltext/download. php?file=jda-v4-id1092.pdf. Accessed December 1, 2019.

16. Hülsmann M, Peters OA, Dummer PMH. Mechanical preparation of root canals: Shaping goals, techniques and means. Endod Topics. 2005;10(1):30-76. doi:10.1111/J.1601-1546.2005.00152.X

17. Tripi TR, Bonaccorso A, Tripi V, Condorelii GG, Rapisarda E. Defects in GT rotary instruments after use: An SEM study. J Endod. 2001;27(12):782-785. doi:10.1097/00004770-200112000-00018

18. Walia HM, Brantley WA, Gerstein H. An initial investigation of the bending and torsional properties of Nitinol root canal files. J Endod. 1988;14(7):346-351. doi:10.1016/s0099-2399(88)80196-1

19. Shen Y, Huang X, Wang Z, Wei X, Haapasalo M. Low environmental temperature influences the fatigue resistance of nickel-titanium files. J Endod. 2018;44(4):626-629. doi:10.1016/j.joen.2017.11.004

20. Pişkin $B$, Türkün M. Stability of various sodium hypochlorite solutions. J Endod. 1995;21(5):253-255. doi:10.1016/s0099-2399(06)80991-x

21. de Hemptinne $F$, Slaus $G$, Vandendael M, Jacquet W, De Moor RJ, Bottenberg $P$. In vivo intracanal temperature evolution during endodontic treatment after the injection of room temperature or preheated sodium hypochlorite. J Endod. 2015;41(7):1112-1125. doi:10.1016/j.joen.2015.02.011

22. Dosanjh A, Paurazas S, Askar M. The effect of temperature on cyclic fatigue of nickel-titanium rotary endodontic instruments. J Endod. 2017;43(5):823-826. doi:10.1016/j.joen.2016.12.026

23. Plotino G, Grande NM, Bellido MM, Testarelli L, Gambarini G. Influence of temperature on cyclic fatigue resistance of ProTaper Gold and ProTaper Universal rotary files. J Endod. 2017;43(2):200-202. doi:10.1016/j.joen.2016.10.014

24. Tanomaru-Filho M, Espir CG, Venção AC, Macedo-Serrano N, Camilo-Pinto J, Guerreiro-Tanomaru J. Cyclic fatigue resistance of heat-treated nickel-titanium instruments. Iran Endod J. 2018;13(3):312-317. doi:10.22037/iej.v13i3.18637 